University of Nebraska - Lincoln

DigitalCommons@University of Nebraska - Lincoln

2007

\title{
On the Lack of Participating Policy Usage by Stock Insurance Companies
}

\author{
Geoffrey C. Friesen \\ University of Nebraska-Lincoln, gfriesen2@unl.edu
}

Follow this and additional works at: https://digitalcommons.unl.edu/financefacpub

Part of the Finance and Financial Management Commons

Friesen, Geoffrey C., "On the Lack of Participating Policy Usage by Stock Insurance Companies" (2007). Finance Department Faculty Publications. 4.

https://digitalcommons.unl.edu/financefacpub/4

This Article is brought to you for free and open access by the Finance Department at DigitalCommons@University of Nebraska - Lincoln. It has been accepted for inclusion in Finance Department Faculty Publications by an authorized administrator of DigitalCommons@University of Nebraska - Lincoln. 


\title{
On the Lack of Participating Policy Usage by Stock Insurance Companies
}

\author{
Geoffrey Friesen
}

University of Nebraska-Lincoln

\begin{abstract}
Stock insurers can reduce or eliminate agency conflicts between policyholders and stockholders by issuing participating insurance. Despite this benefit, most stock companies don't offer participating contracts. This study explains why. We study an equilibrium with both stock and mutual insurers in which stockholders set premiums to provide a fair expected return on their investment, and with a policyholder who chooses the insurance contract that maximizes her expected utility. We demonstrate that stockholders cannot profitably offer fully participating contracts, but can profitably offer partially participating insurance. However, when the policyholder participation fraction is high, the fair-return premium is so large that the policyholder always prefers fully participating insurance from the mutual company. Policies with lower levels of policyholder participation are optimal for policyholders with relatively high risk aversion, though such policies are usually prohibited by insurance legislation. Thus, the reason stock insurers rarely issue participating contracts isn't because the potential benefits are small or unimportant. Rather, profitability or regulatory constraints simply prevent stock insurers from exercising those benefits in equilibrium.
\end{abstract}

\section{Introduction}

The roles of owner and customer are distinctly separate in stock insurance companies, and this separation creates incentive conflicts not present in mutual companies. ${ }^{1}$ For example, stockholders have an incentive to expropriate policyholder wealth by increasing the volatility of the firm's assets, creating a conflict similar to Jensen and Meckling's (1976) stockholder-bondholder conflict. Also, managers

\footnotetext{
${ }^{1}$ Ownership rights in a mutual company include membership rights and insurance policy rights. Disagreement over the exact meaning of membership rights has led to a great deal of recent controversy (for example, see Belth (1997) and Adkins (1997)). For the purposes of this paper, the controversy is incidental, since the key feature is the presence (or absence) of the stockholder-policyholder incentive conflict. This conflict is present in all stock companies, and absent in all mutual companies, regardless of the exact definition of membership rights.
} 
of a stock insurer may rationally forego certain positive net present value projects, and this underinvestment problem can be particularly severe among insurers with high leverage.

Stock insurers can reduce or eliminate these incentive conflicts by issuing participating insurance policies. Participating policies pay dividends based on deviations of actual claims, interest, and expenses from the assumptions built into the premium, thus allowing policyholders to share in the insurer's aggregate profits (Black and Skipper, 2000). Garven and Pottier (1995) develop a formal model of participating insurance and demonstrate that participating policies can eliminate the risk-shifting conflict between a stock company's policyholders and stockholders. Krishnaswami and Pottier (2001) show that although participating business can lead to problems of reduced managerial effort, it effectively eliminates both the underinvestment and risk-shifting conflicts.

And yet, it is an empirical fact that stock insurance companies rarely issue participating business. ${ }^{2}$ In light of the potential benefits, the general absence of participating policies among stock insurers is not well understood. The primary objective of the current study is to develop a formal model that helps explain the strong positive association between participating contracts and the mutual organization. ${ }^{3}$

It should be noted that the general absence of participating contracts among stock insurers is not necessarily evidence against the models of Garven and Pottier (1995) and Krishnaswami and Pottier (2001). Indeed, we would argue that those models are not only valid, but offer important insights into the benefits of participating business for stock insurers. In fact, Krishnaswami and Pottier (2001) offer one potential explanation for stock insurers' use of participating policies. Specifically, their model suggests that participating policy usage is dictated by a tradeoff between the benefits of reducing the risk-shifting and underinvestment conflicts and the costs of exacerbating the manager-stockholder conflict. Their model does a good job explaining cross-sectional variation among the subset of stock insurers that issue participating contracts. At the margin, the cost-benefit argument seems plausible.

However, explaining the complete absence of participating contracts among the majority of stock insurers requires that the benefits of such contracts are usually too small to matter. We offer an alternative explanation, one that is fully consistent with participating contract benefits of first-order importance as described in Garven and Pottier (1995) and Krishnaswami and Pottier (2001). Specifically,

\footnotetext{
${ }^{2}$ For example, Krishnaswami and Pottier (2001) find that 83 percent of stock insurers in their sample had no participating business at all. Among the 17 percent of stock insurers issuing participating insurance, only 7.1 percent of their in-force business was classified as participating. In contrast, Garven and Pottier (1995) find that among a sample of mutual companies, all had some participating business, with an average of 94.2 percent of in-force business classified as participating.

${ }^{3}$ The strong association between mutual companies and participating insurance has resulted in some confusion in the literature, with a number of papers using the terms "mutuality" and "participating insurance" interchangeably. Smith and Stutzer (1995) examine the historical evolution of participating insurance, and note that neither their paper nor any other has formally addressed why the use of participating insurance contracts is so strongly associated with the mutual organization.
} 
we develop a general equilibrium model of participating insurance contracts utilizing the contingent claims framework of Doherty and Garven (1986). In our model, it's not that the benefits of issuing participating contracts are small or unimportant. Rather, profitability or regulatory constraints simply prevent stock insurers from exercising those benefits in equilibrium.

To preview, our model includes both stock and mutual insurance companies, as well as a policyholder who chooses the insurance contract which maximizes her expected utility. In the model, the mutual company issues only fully participating insurance. The stock company, on the other hand, can issue both participating and nonparticipating insurance contracts, and sets premiums on all policies to provide stockholders with a fair expected return. ${ }^{4}$ For the stock insurer, we consider both fully and partially participating contracts, the latter of which entitles both stockholders and policyholders to predetermined fractions of aggregate insurer profits. ${ }^{5}$

A key feature of our model is that we simultaneously consider the stock insurer's decision to sell insurance (the fair-return problem) and the policyholder's optimal purchase decision (the policyholder choice problem). This turns out to be critical because, as we show, the stockholders' fair-return premium frequently exceeds the price policyholders are willing to pay. In particular, when the policyholder participation fraction is high, the stockholders' fair-return premium is so large that the utility-maximizing policyholder always prefers fully participating insurance issued by the mutual company. In these instances, stockholders could reduce their various agency conflicts by issuing participating contracts if they could find policyholders willing to purchase them. However, these contracts are not optimal for any policyholder, and thus are never observed in equilibrium.

At lower levels of policyholder participation, a different story emerges. Again, stockholders willingly offer partially participating insurance contracts, but now such contracts are also optimal for policyholders with relatively high levels of riskaversion. ${ }^{6}$ Given their feasibility, it would seem that such partially participating contracts would be desirable from the perspective of the stock insurer, since they offer both profitability and a reduction in stockholder-policyholder agency conflicts. In light of this, it is puzzling that such contracts are so rarely observed. We suggest that the absence can be traced directly to specific insurance legislation which pro-

\footnotetext{
${ }^{4}$ While this framework allows insurers to "set" the premium, the equilibrium premium is defined as the premium at which the market value of the stockholders' claim equals the stockholders' paid-in equity. This equilibrium premium is constrained to be no greater than the premium which provides a fair expected return. For a given set of investment and underwriting risks, all insurers will charge the same fair-return premium. In this sense, insurance companies are price takers, where the price includes a normal profit (equal to the market-based fair expected return), but zero economic profit.

${ }^{5}$ As we demonstrate below, the extreme case of fully participating insurance never obtains with a stock insurer. That is, when a stock company sets premiums to provide a fair expected return on stockholders investment, stockholders will never find it optimal to offer fully participating insurance. The obvious reason is that fully participating contracts require the stockholders to bear a certain amount of downside risk (related to unexpected claims or unfavorable investment returns), yet exclude the stockholders from potential profits.

${ }^{6}$ A limiting case of our model demonstrates that the most risk-averse policyholders optimally purchase nonparticipating insurance issued by the stock company.
} 
hibits partially participating contracts with low levels of policyholder participation. To summarize our results, the partially participating contracts allowed by law are undesirable to policyholders, while the partially participating contracts desired by certain policyholders aren't allowed by law. As a practical matter then, stock insurance companies and participating policies are often incompatible.

Contingent claims models similar to ours have been applied to both property-liability insurance (Doherty and Garven, 1986) and life insurance (Garven and Pottier, 1995 and Krishnaswami and Pottier, 2001). While we feel our two-period model most literally resembles a property-liability contract, Garven and Pottier (1995) note that participating payoff features like ours depend both on claims and interest, and thus also resemble the payoff structure of cash-value universal life insurance. ${ }^{7}$ In addition, policyholder risk aversion plays an important role in our model. We find it more sensible to talk about the risk aversion of individuals rather than corporations, which suggests that our model is most applicable to personal, as opposed to commercial, insurance lines.

This study also contributes to our understanding of the relationship between preferences and participation in aggregate losses. More specifically, we demonstrate that for individuals with constant absolute risk aversion (CARA) utility, the desire to purchase participating insurance is decreasing in risk aversion. In other words, policyholders with low levels of risk aversion will tend to associate with participating mutual contracts, while those with high levels of risk aversion will desire partially or nonparticipating insurance. The intuitive reason for this is straightforward: participating in aggregate (risky) profits exposes an insured to additional risk, and will be chosen only by those most willing to bear such risk. This result is consistent with the results of Borch (1968), but contrasts with the assumptions in more recent work on organizational form (see e.g., Remmers, 2003).

The rest of the article is structured as follows: Section 1 reviews the related literature. Section 2 develops a basic model of nonparticipating insurance where stockholders use a multivariate contingent claims framework to set premiums that produce a fair expected return. We then extend the basic model to allow policyholder participation in aggregate profits. Section 3 examines the policyholder choice problem and describes an equilibrium in which policyholders choose the optimal insurance contract when stockholders set premiums to provide a fair expected return. Section 4 concludes.

\section{Insurance Contract Equilibrium}

A general equilibrium analysis of insurance contracts involves an examination of both the policyholder's decision to purchase insurance and the insurance company's decision to sell. The "policyholder-choice problem" of choosing the optimal level of nonparticipating insurance coverage is well understood in the context of both nonparticipating (Borch, 1968 and Arrow, 1974) and participating contracts (Doherty, 1991; Doherty and Dionne, 1993; Smith and Stutzer, 1995). All

\footnotetext{
${ }^{7}$ That said, permanent life insurance policies, such as whole life or universal life, have a number of features not captured by our model. For example, expected claims, cash values, surrender values, and dividends vary period-to-period. This variation not only makes it difficult for buyers to know the price they are paying for coverage, but also cannot be adequately modeled in this (or any other) two-period model.
} 
of these studies either assume insurers are risk-neutral or impose a zero-profit condition when setting premiums. That is, none of these studies explicitly incorporate the stockholder problem of determining the risk-based premium necessary to generate an acceptable expected return. Such assumptions simplify the analysis, and are justified when developing models to understand the basic properties of policyholder choice.

Nevertheless, the assumptions of risk-neutrality and zero-profit are unrealistic because they ignore the premium an insurer demands for bearing risk. Stockholders supply capital to a stock insurer only when they expect to earn a fair return on their investment. The problem of setting premiums that generate fair expected returns is often referred to as the "fair return problem," and a second strand of literature has examined this problem. For instance, the problem of setting fair premiums has been analyzed in a Capital Asset Pricing Model (CAPM) context by Hill (1979) and Fairley (1979), and in an option pricing framework that accounts for the risk of default and the value of tax liabilities (Doherty and Garven, 1986). These articles acknowledge the stockholders' need to earn a fair return, but they do not explicitly incorporate the policyholder choice aspect of the problem. That is, although they calculate the premiums stockholders must charge to earn an acceptable return, they do not ask how much (if any) insurance risk-averse policyholders will optimally purchase at the fair-return price.

The next section develops an equilibrium model of participating insurance contracts that combines the policyholder choice and stockholder return problems. We are unaware of any articles that combine the policyholder choice problem and stockholder return problem in this way. As such, this aspect of our model represents an additional contribution of the current study.

\section{A Model of Nonparticpating Insurance Policies}

This section utilizes the option pricing framework developed in Doherty and Garven (1986) to calculate the premium stockholders must charge to provide a fair expected return on both nonparticipating and participating contracts. Later in Section 3, we will build upon this model to analyze the optimal purchase decisions by policyholders, recognizing that an equilibrium can exist only when stockholders set a fair-return premium and when policyholders find it desirable to purchase insurance at that price.

\section{A Basic Model of Nonparticipating Insurance}

We present a one-period model of the insurance firm that is a special case of the model in Doherty and Garven (1986). While acknowledging that in practice, mutual insurers issue some nonparticipating business, we examine the nonparticipating policy in the context of a stock-insurance company, where such policies are most common.

In period zero, residual claimholders contribute equity of $S_{0}$, and the policyholder pays a premium of $\mathrm{P}_{0}$, producing a total time zero cash flow of

$$
Y_{0}=\left(S_{0}+P_{0}\right)
$$

At the end of the period, claims to the policyholder are discharged and tax liabilities paid, with any excess assets reverting to the residual claimholders. The total 
terminal cash flow (before payment of claims) is

$$
\tilde{Y}_{1}=\left(S_{0}+P_{0}\right)\left(1+\tilde{r}_{i}\right)
$$

where $\tilde{r}_{i}$ is the stochastic investment income earned during the period. ${ }^{8}$ Define $\tilde{L}_{1}$ to be the insured's end-of-period claim cost and $\tau$ the corporate tax rate. The terminal cash flow, $\tilde{Y}_{1}$, is divided among the various claimholders, with the policyholder receiving $\tilde{H}_{1}$, the government receiving $\tilde{T}_{1}$, and the residual claimholders receiving the excess (if any) $\tilde{E}_{1} \cdot{ }^{9}$ Then,

$$
\begin{aligned}
& \tilde{H}_{1}=\tilde{Y}_{1}-\max \left(\tilde{Y}_{1}-\tilde{L}_{1}, 0\right)=\max \left(\min \left(\tilde{L}_{1}, \tilde{Y}_{1}\right), 0\right) \\
& \tilde{T}_{1}=\max \left(\tau\left(\tilde{Y}_{1}-Y_{0}+P_{0}-\tilde{L}\right), 0\right) \\
& \tilde{E}_{1}=\max \left(\tilde{Y}_{1}-\tilde{H}_{1}-\tilde{T}_{1}, 0\right) .
\end{aligned}
$$

Each of these claims can be expressed as options, and can thus be valued using the appropriate option-pricing methodology. The value of the claims at time zero will be given by:

$$
\begin{aligned}
H_{0} & =V\left(\tilde{Y}_{1}\right)-C\left(\tilde{Y}_{1} ; \tilde{L}\right) \\
T_{0} & =\tau C\left(\tilde{Y}_{1}-Y_{0}+P_{0}, \tilde{L}\right) \\
V_{e} & =V\left(\tilde{Y}_{1}\right)-\left[H_{0}+T_{0}\right] \\
& =C\left(\tilde{Y}_{1} ; \tilde{L}\right)-\tau C\left(\tilde{Y}_{1}-Y_{0}+P_{0}, \tilde{L}\right) \\
& \equiv C_{1}-\tau C_{2}
\end{aligned}
$$

where $V(\cdot)$ is the valuation operator and $C(\mathrm{~A} ; \mathrm{B})$ represents the current market value of a European call option written on an asset with terminal price $A$ and strike price $B . H_{0}$ represents the value of the policyholder's claim at time zero, $T_{0}$ represents the value of the government's claim, and $V_{e}$ is the time zero value of the stockholders' claim. The term $C_{1}$ represents the stockholders' call option on the firm's assets. If the pretax value of equity is positive, the stockholders have a valuable claim. When the cash flow to equity is negative (i.e. aggregate claims exceed the value of the firm's assets), stockholders have the ability to (at least partially) default on their obligation to the policyholder. ${ }^{10}$ The value of the stockhold-

\footnotetext{
${ }^{8}$ Doherty and Garven include a funds-generating coefficient in their model of investment returns, representing an adjustment to compensate for the difference between the period in the model and the average delay between receipt of premiums and payment of policyholder claims. For simplicity, we assume $\mathrm{k}=1$, although the results are qualitatively identical for the more general case.

${ }^{9}$ Doherty and Garven include a parameter $\theta$ to reflect the tax-exempt securities that corporations may hold. Without loss of generality, we set $\theta=1$.
} 
ers' claim is reduced by government's call option on a fraction of taxable income, given by $\tau C_{2}$.

Stockholders charge a premium, $P_{0}$, which provides them a fair expected return. The value of the stockholders' equity claim, given in Equation (8), is increasing in the premium $P_{0}$. Stockholders calculate $P_{0}$ so that the value of their equity claim, $V_{e}$, is equal to the initial equity investment $S_{0}$, which is determined exogenously. Since $\tilde{Y}_{1}$ and $Y_{0}$ are functions of $S_{0}$ and $P_{0}$, we can rewrite Equation (8) to characterize the premium, $P_{0}^{*}$, that will produce the fair return to stockholders:

$$
V_{e}=C\left(\tilde{Y}_{1}\left(P_{0}^{*}\right) ; \tilde{L}\right)-\tau\left(\tilde{Y}_{1}\left(P_{0}^{*}\right)-Y_{0}\left(P_{0}^{*}\right)+P_{0}^{*} ; \tilde{L}\right)=S_{0}
$$

Equation (9) can be interpreted as follows: Given the distribution of investment returns $\left(\tilde{r}_{i}\right)$ and claims $(\tilde{L})$, and an exogenously determined equity investment, $S_{0}$, there exists a unique premium, $P_{0}^{*}$, such that the value of the stockholders' equity claim equals the initial investment, $S_{0}{ }^{11,12}$

\section{Properties of Nonparticipating Insurance under Normality Assumption}

Assuming aggregation conditions hold (Rubinstein, 1974) Equation (9) can be priced claims using a discrete-time, risk-neutral-valuation approach. Using this methodology requires one to make certain assumptions about the joint distribution of the underlying stochastic variables $\tilde{r}_{i}$ and $\tilde{L}$, as well as the shape of the representative investor's utility function. Brennan (1979) demonstrates that the risk-neutral valuation approach holds under the assumptions that: (1) returns and claims are jointly normally distributed and the representative investor exhibits CARA; or (2) returns and claims are jointly lognormally distributed and the representative investor exhibits constant relative risk aversion (CRRA). Stapleton and Subrahmanyam (1984) extend Brennan's results to price multivariate contingent claims, such as the call option with a stochastic exercise price considered here. The remainder of the article uses the option pricing framework from Staple-

\footnotetext{
${ }^{10}$ Note that this analysis ignores the impact of insurance guaranty funds from the policyholder's perspective. However, the presence of guaranty funds does not change the premiums stockholders must charge to provide themselves a fair expected return, and as such does not impact this part of the analysis.

${ }^{11}$ While $\tilde{r}_{i}$ does not appear in the expression for Equation (9), it does affect the value of stockholder equity through $\tilde{Y}_{1}$ (see definition in Equation 2).

12 The premium is constrained to be no greater than the premium which provides a fair expected return, and for a given set of investment and underwriting risks, all insurers will charge the same fair-return premium. A sufficient condition for this is that the cost of capital across insurers is equal to the equilibrium expected return. If an insurer's cost of capital is lower than the equilibrium expected return, it would be possible for an insurer to profitably offer a contract at a lower premium. In addition, insurance rate regulation might prevent the insurer from charging the fair-return premium. In the latter case, the insurer might find it optimal to offer a contract at the lower, regulated premium, so long as the resulting expected return exceeded the insurer's hurdle rate.
} 
ton and Subrahmanyam (1984), along with the assumption of CARA and jointnormality to evaluate the expression in Equation (9). ${ }^{13}$

The value of the first call option, $C_{1}$, can be written as

$$
C_{1}=C\left(\tilde{Y}_{1} ; \tilde{L}\right)=R_{f}^{-1} \int_{-\infty}^{\infty} \int_{-\infty}^{\infty} \max \left[\tilde{Y}_{1}-\tilde{L}, 0\right] \hat{f}\left(\tilde{Y}_{1}, \tilde{L}\right) d \tilde{Y}_{1} d \tilde{L}
$$

where $\tilde{f}\left(\tilde{Y}_{1}, \tilde{L}\right)$ is the bivariate risk-neutral probability density function of $\tilde{Y}_{1}$ and $\tilde{L}$. The relevant risk-neutral expectations are:

$$
\begin{aligned}
\hat{E}\left(\tilde{Y}_{1}\right) & =E\left(\tilde{Y}_{1}\right)-\lambda \operatorname{cov}\left(\tilde{Y}_{1}, \tilde{r}_{m}\right) \\
\lambda & =\text { the market price of risk } \\
& =\frac{\left[\mathrm{E}\left(\tilde{r}_{\mathrm{m}}\right)-r_{f}\right]}{\sigma_{m}^{2}} \\
\hat{E}(\tilde{L}) & =E(\tilde{L})-\lambda \operatorname{cov}\left(\tilde{L}, \tilde{r}_{m}\right) .
\end{aligned}
$$

Equation (12) can be rewritten by defining $\tilde{X} \equiv \tilde{Y}_{1}-\tilde{L}$, which is the excess of assets over claims. The risk-neutral expectation of $\tilde{X}_{\tilde{X}}$ is given by $\hat{E}(\tilde{X})=\hat{E}\left(\tilde{Y}_{1}\right)$ - $\hat{E}(\tilde{L})$ $=\left(S_{0}+P_{0}\right)\left(1+r_{f}\right)-\hat{E}(\tilde{L})$, and the variance of $\tilde{X}$ is $\sigma_{x}^{2}=\left(S_{0}+P_{0}\right)^{2} \sigma_{i}^{2}+\sigma_{L}^{2}-2\left(S_{0}+P_{0}\right)$ $\operatorname{cov}\left(\tilde{L}, \tilde{r}_{i}\right)$. Doherty and Garven (1986) show that the value of the stockholders' call option, $C_{1}$, is given by

$$
C_{1}=R_{f}^{-1}\left[\hat{E}(\tilde{X}) N\left[\frac{\hat{E}(\tilde{X})}{\sigma_{x}}\right]+\sigma_{x} n\left[\frac{\hat{E}(\tilde{X})}{\sigma_{x}}\right]\right]
$$

where $N[\cdot]$ is the standard normal cumulative distribution function, and $n[\cdot]$ is the standard normal density function.

The value of the government's call option on taxable income is $\tau C_{2}$, and $C_{2}$ can be written as

$$
\begin{aligned}
C_{2} & =C\left(\tilde{Y}_{1}-Y_{0}+P_{0} ; \tilde{L}\right) \\
& =R_{f}^{-1} \int_{-\infty}^{\infty} \int_{-\infty}^{\infty} \max \left[\tilde{Y}_{1}-Y_{0}+P_{0}-\tilde{L}, 0\right] \hat{f}\left(\tilde{Y}_{1}, \tilde{L}\right) d \tilde{Y}_{1} d \tilde{L} .
\end{aligned}
$$

Define the normal variable $W \equiv \tilde{Y}_{1}-Y_{Q}+P_{0}-\tilde{L}$. The risk-neutral expectation of $\tilde{W}$ is given by $\hat{E}(\tilde{W})=\hat{E}\left(\tilde{Y}_{1}\right)-Y_{0}+P_{0}-E(L)=\left(S_{0}+P_{0}\right) \cdot r_{f}+P_{0}-E(\tilde{L})$, and the variance

\footnotetext{
${ }^{13}$ Both claims and investment return processes can also be approximated by a lognormal distribution. However, we use the normal distribution assumption for expositional clarity. Similar results under the lognormality framework are available from the author upon request.
} 


\section{Payoffs}

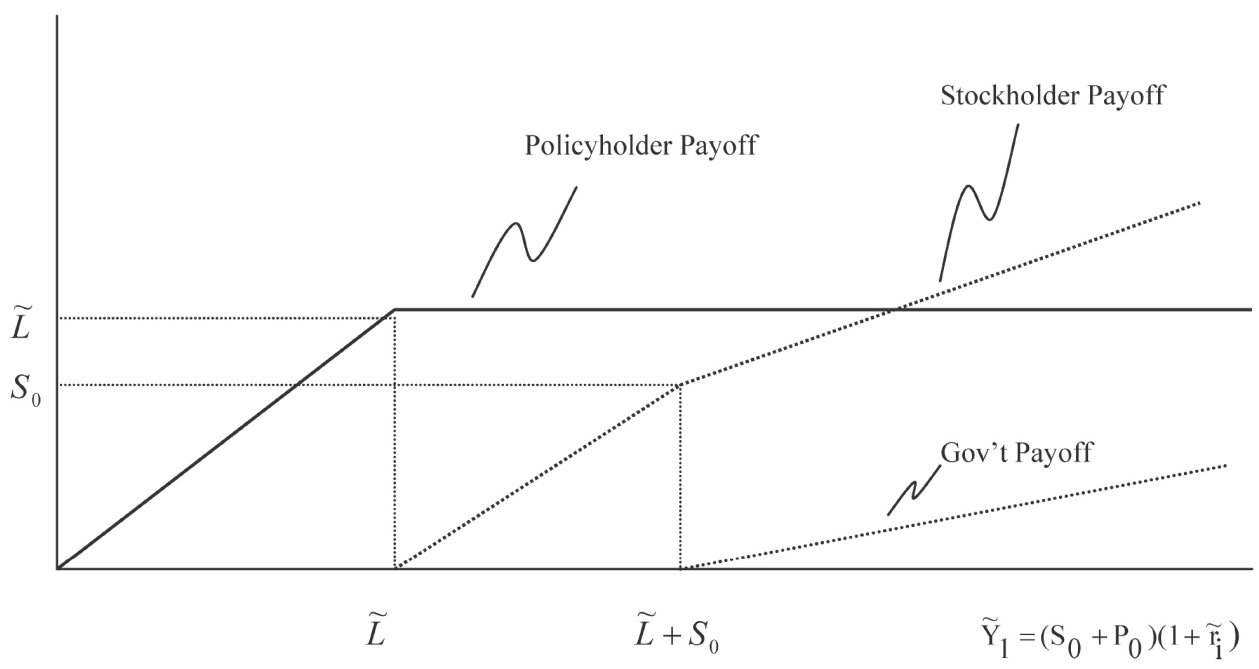

Figure 1. Payoffs Associated with Nonparticipating Insurance. Illustrates the payoffs to policyholders, stockholders, and the government (taxes) associated with a nonparticipating insurance contract. These payoffs are specified by Equations (3)-(5) in the text, respectively.

of $\tilde{W}$ is $\sigma_{W}^{2}=\left(S_{0}+P_{0}\right)^{2} \sigma_{i}^{2}+\sigma_{L}^{2}-2\left(S_{0}+P_{0}\right) \operatorname{cov}\left(\tilde{L}, \tilde{r}_{i}\right)$. Doherty and Garven show that (12) can be expressed as

$$
C_{2}=R_{f}^{-1}\left[\hat{E}(\tilde{W}) N\left[\frac{\hat{E}(\tilde{W})}{\sigma_{W}}\right]+\sigma_{W n}\left[\frac{\hat{E}(\tilde{W})}{\sigma_{W}}\right]\right]
$$

Using (11) and (13) allows us to write the market value of equity as:

$V_{e}=R_{f}^{-1}\left[\hat{E}(\tilde{X}) N\left[\frac{\hat{E}(\tilde{X})}{\sigma_{x}}\right]-\tau \hat{E}(\tilde{W}) N\left[\frac{\hat{E}(\tilde{W})}{\sigma_{W}}\right]+\sigma_{x} n\left[\frac{\hat{E}(\tilde{X})}{\sigma_{x}}\right]-\tau \sigma_{W} n\left[\frac{\hat{E}(\tilde{W})}{\sigma_{W}}\right]\right]$.

Given exogenously specified parameter values for the required equity $\left(\mathrm{S}_{0}\right)$, the insured loss $\left(E(\tilde{L}), \sigma_{L}\right)$, the invested assets $\left(\sigma_{i^{\prime}} \rho_{i L^{\prime}} \beta_{i}\right)$, the tax rate $(\tau)$, and capital markets parameters $\left(r_{f}, \mathrm{E}\left(\tilde{r}_{m}\right), \sigma_{m}\right)$, stockholders solve Equation (12) for the premium, $P_{0}^{*}$, that equates $V_{e}$ with the $S_{0}$. Stockholders are willing to insure the loss $\tilde{L}$ at this price, since the premium is calculated to provide stockholders with a "fair" expected rate of return. In this context, "fair" means that in return for the initial investment of $S_{0}$, the stockholders receive a claim with a capital market value also equal to $S_{0}$. Of course, the stockholders' expected payoff is actually greater than $S_{0}$, but the riskiness of the claim reduces the claim's value from the expected payoff to $S_{0}$. Figure 1 displays the payoffs to various claimants under nonparticipating insurance. 


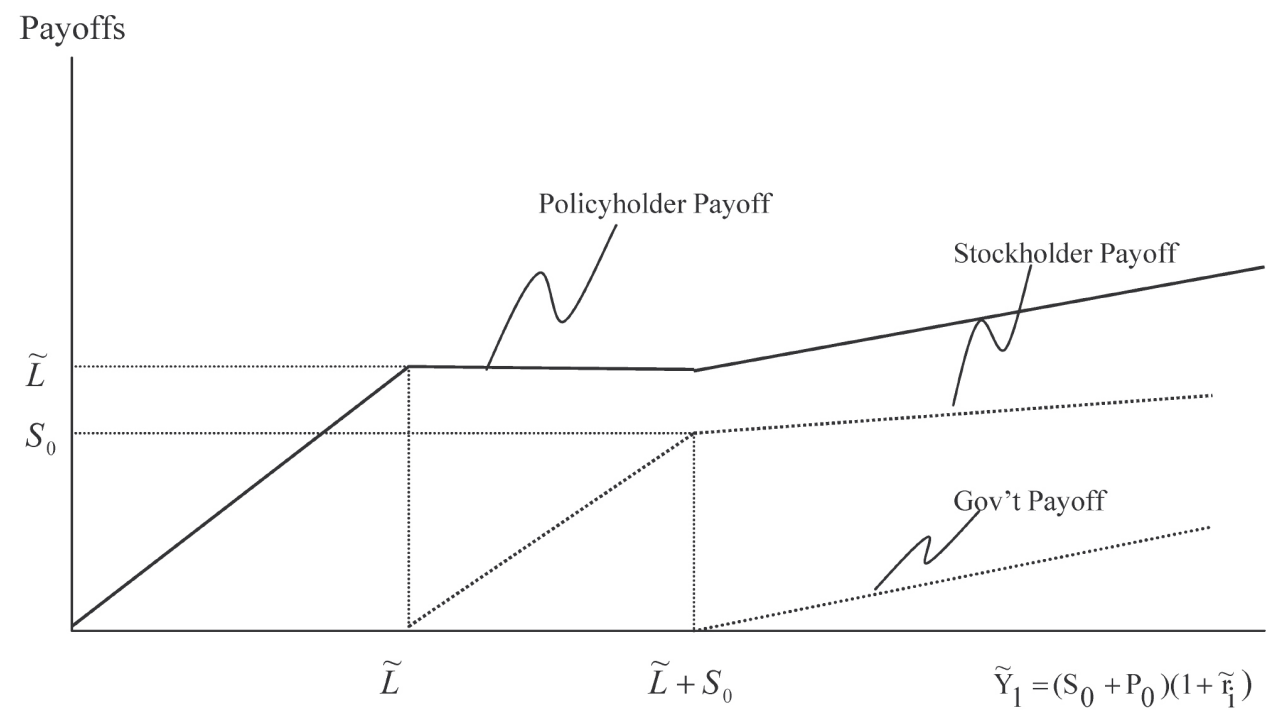

Figure 2. Payoffs Associated with Partial Participating Insurance $(\gamma<1)$. Illustrates the payoffs to policyholders, stockholders, and the government (taxes) associated with a nonparticipating insurance contract. These payoffs are specified by Equations (15)-(17) in the text, respectively.

Incorporating a Participation Feature

Participating insurance allows the policyholder to share in some fraction, $\gamma$, of the aggregate profits (losses) of the insurance company via policy dividends (or assessments). ${ }^{14}$ The payoffs to the various claimants under participating insurance are depicted in Figure 2 (partially participating) and Figure 3 (fully participating.). Total firm assets, $Y_{1}$, are displayed on the horizontal axis, while payoffs are on the vertical axis.

The nonparticipating payoffs from Section $2 \mathrm{~B}$ can be modified to reflect the participation benefits, with the difference being that the policyholder receives a fraction, $\gamma$, of after-tax income, leaving only $(1-\gamma)$ of the after-tax income for stockholders. Thus, the terminal cash flow, $\tilde{Y}_{1}$, is divided among the various claimholders, with the participating policyholder receiving $\tilde{H}_{1}^{p}$, the government receiving $\tilde{T}_{1}^{p}$, and the stockholders receiving the excess $\tilde{E}_{1}^{p}$. It is assumed that the return of stockholder equity does not constitute a taxable distribution to stockholders. That is, taxable income is defined to equal end-of-period assets, minus claims, minus stockholder equity:

$$
\tilde{H}_{1}^{P}=\max \left(\min \left(\tilde{L}_{1}, \tilde{Y}_{1}\right), 0\right)+y \max \left((1-\tau)\left(\tilde{Y}_{1}-S_{0}-\tilde{L}\right), 0\right)
$$

\footnotetext{
${ }^{14}$ In our model, assessments occur only when the investment income is below -100 percent, that is, when $\tilde{Y}_{1}$ is negative (see Equation (3)). As long as the insurance company invests in financial assets with limited liability, the theoretically possible assessment will not come to pass.
} 


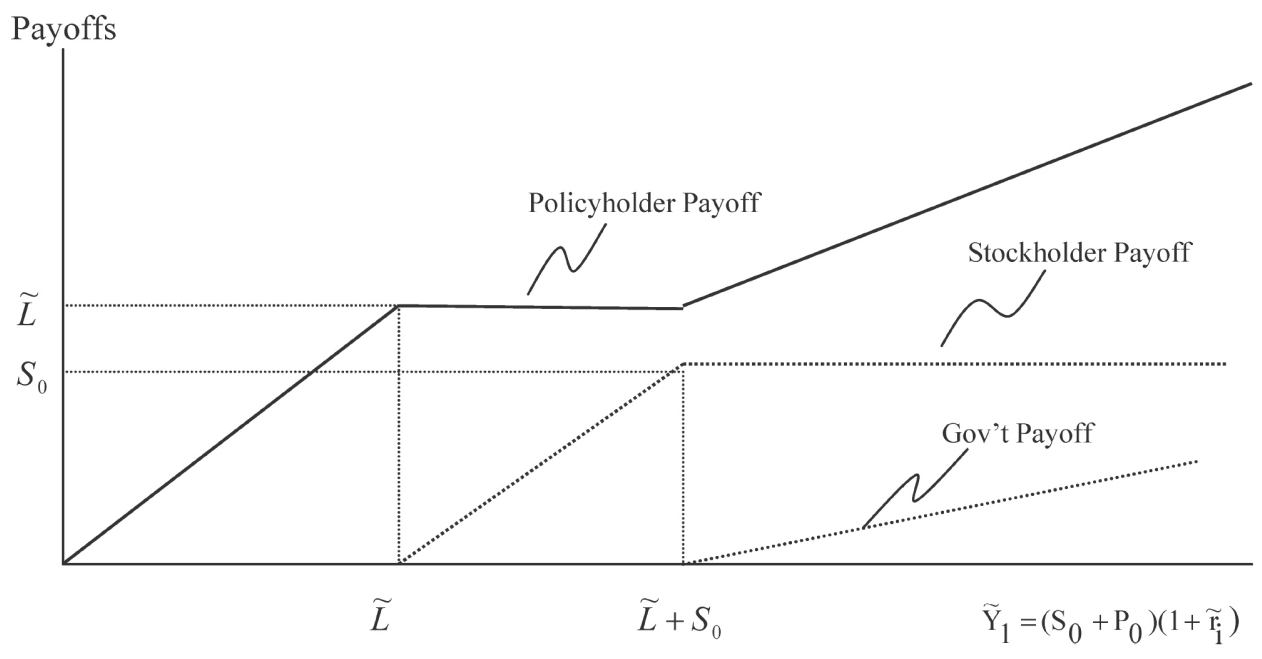

Figure 3. Payoffs Associated with Fully Participating Insurance $(\gamma=1)$. Illustrates the payoffs to policyholders, stockholders, and the government (taxes) associated with a nonparticipating insurance contract. These payoffs are specified by Equations (15)-(17) in the text, respectively.

$$
\begin{aligned}
& \tilde{T}_{1}^{P}=\max \left(\tau\left(\tilde{Y}_{1}-S_{0}-\tilde{L}\right), 0\right) \\
& \tilde{E}_{1}^{P}=\max \left(\tilde{Y}_{1}-\tilde{H}_{1}^{P}-\tilde{T}_{1}^{P}, 0\right)
\end{aligned}
$$

The value of the claims at time zero will be given by:

$$
\begin{aligned}
H_{0}^{P} & =V\left(\tilde{Y}_{1}\right)-C\left(\tilde{Y}_{1} ; \tilde{L}\right)+\gamma(1-\tau) C\left(\tilde{Y}_{1}-S_{0} ; \tilde{L}\right) \\
T_{0}^{P} & =\tau C\left(\tilde{Y}_{1}-S_{0}-\tilde{L} ; \tilde{L}\right) \\
V_{e}^{P} & =V\left(\tilde{Y}_{1}\right)-\left(H_{o}^{P}+T_{o}^{P}\right) \\
& =C\left(\tilde{Y}_{1} ; \tilde{L}\right)-(\tau+\gamma(1-\tau)) C\left(\tilde{Y}_{1}-S_{0}, \tilde{L}\right) \\
& \equiv C_{1}-(\tau+\gamma(1-\tau)) C_{2} .
\end{aligned}
$$

The value of the call options $C_{1}$ and $C_{2}$ are the same under participating insurance as they are under nonparticipating insurance. Once again, given parameter values for the variables $S_{0^{\prime}} \sigma_{i^{\prime}} E(L), \sigma_{L^{\prime}} \rho_{i L^{\prime}} r_{f^{\prime}} \tau, \beta_{i^{\prime}} E\left(\tilde{r}_{m}\right), \sigma_{m^{\prime}}$ stockholders solve Equation (20) for the premium, $P_{0}^{P *}$, that equates $V_{e}^{P}$ with the assumed value of $S_{0}$. This is the lowest premium stockholders will offer, as it provides stockholders with a fair expected rate of return on participating insurance.

From Equation (20) it is clear why fully participating insurance $(\gamma=1)$ cannot be associated with stock companies. Under fully participating insurance, the 
value of stockholders' claims is given by $V_{e}^{P}=C_{1}-C_{2}=V\left(\max \left(\tilde{Y}_{1}-\tilde{L}, 0\right)-\right.$ $V\left(\max \left(\tilde{Y}_{1}-S_{0}-\tilde{L}, 0\right)\right)$. This payoff structure is shown in Figure 3. The payoff to stockholders is zero when $\tilde{Y}_{\mathcal{1}}<\tilde{L}$, between zero and $S_{0}$ when $0<\tilde{Y}_{1}-\tilde{L}<S_{0}$, and equal to $S_{0}$ when $S_{0}<\tilde{Y}_{1}-\tilde{L}$. The value of this claim is strictly less than $S_{0}$ and does not depend on the premium $P_{0}$. Stockholders cannot earn a fair rate of return no matter how large a premium they charge. This is because stockholders continue to bear some of the firm's downside risk, but enjoy none of the upside benefits since all profits accrue to the participating policyholders. ${ }^{15}$

Thus, stock insurers will never issue fully participating insurance, since such contracts cannot be offered on a profitable basis. It is possible for stock insurers to profitably issue partially participating insurance $(\gamma<1)$, and the next section demonstrates that such contracts are optimal for some policyholders.

\section{The Policyholder Problem}

Given the fair return premiums charged by the stockholders, the policyholder's problem is to choose the participation level that maximizes expected utility. Recall that the stock insurer offers nonparticipating policies at a price of $P_{0}^{*}$ and partially participating policies at a price of $P_{0}^{P *}$, where prices are calculated using the framework developed in Section 2. To simplify notation, we generalize slightly the interpretation for $P_{0}^{P *}$ allowing it to represent the premium stockholders charge for any given level of participation. Thus, $P^{P *}$ is a function of $\gamma$, and different levels of $\gamma$ will produce different values of $P^{P *}$.

We assume that the mutual company issues only fully participating policies, with the premium for a fully participating mutual contract equal to $P_{0}^{*}+S_{0}$. That is, the cost of a fully participating mutual insurance contract is equivalent to the cost of a nonparticipating stock policy plus the required initial equity investment. The mutual customer effectively purchases the stockholders' position for $S_{0}$, obtaining the rights to after-tax income and bearing the additional downside risk that occurs when assets exceed claims, but are less than claims plus initial equity.

The option pricing framework used by stockholders to calculate premiums prevents us from obtaining closed-form solutions for the optimal level of policyholder participation. For this reason, we utilize a numerical simulation to characterize the optimal degree of participation as a function of policyholder risk aversion.

\section{Numerical Simulation of Fair-Return Premiums}

Using the option pricing framework from Section 2, we solve for the premiums stockholders charge for various levels of policyholder participation, as well as the fully participating premium charged by the mutual insurer. The parameter values utilized in the simulation are reported in Table 1, panel (a). Table 1, panel (b) contains the fair-return premiums for various levels of policyholder participation.

Under the assumed parameterization with an expected loss of $\$ 1,000$, the nonparticipating premium equals $P_{0}^{*}=\$ 1,008.11$, since at this premium, $V_{e}=S_{0}=\$ 500$.

15 The limited liability nature of the equity claim limits the downside risk. In this context, the downside risk refers to the possibility of losing the initial equity investment, $S_{0}$. 
Table 1. Premiums for Various Levels of Policyholder Participation

\begin{tabular}{|c|c|c|}
\hline \multicolumn{3}{|c|}{ Panel (a) } \\
\hline $\begin{array}{l}E(\tilde{L})=1000 \\
\sigma_{L}=400 \\
r_{f}=5 \% \\
\tau=35 \% \\
\sigma_{m}=20.0 \%\end{array}$ & & $\begin{array}{l}\beta_{i}=0.50 \\
E\left(r_{i}\right)=8.5 \% \\
\sigma_{i}=10.0 \% \\
E\left(r_{m}\right)=12 \% \\
S_{0}=500\end{array}$ \\
\hline \multicolumn{3}{|c|}{ Panel (b) } \\
\hline $\begin{array}{l}\text { Participation Level } \\
(\gamma)\end{array}$ & $\begin{array}{l}\text { Stock Company } \\
\text { Premium } P_{0}^{P^{*}}\end{array}$ & $\begin{array}{l}\text { Fully Participating Mutual } \\
\text { Premium } P_{0}^{*}+S_{0}\end{array}$ \\
\hline 0 & $1,008.11$ & $\mathrm{n} / \mathrm{a}$ \\
\hline 0.1 & $1,027.92$ & $\mathrm{n} / \mathrm{a}$ \\
\hline 0.2 & $1,050.25$ & $\mathrm{n} / \mathrm{a}$ \\
\hline 0.3 & $1,075.83$ & $\mathrm{n} / \mathrm{a}$ \\
\hline 0.4 & $1,105.75$ & $\mathrm{n} / \mathrm{a}$ \\
\hline 0.5 & $1,141.00$ & $\mathrm{n} / \mathrm{a}$ \\
\hline 0.6 & $1,187.00$ & $\mathrm{n} / \mathrm{a}$ \\
\hline 0.7 & $1,246.84$ & $\mathrm{n} / \mathrm{a}$ \\
\hline 0.8 & $1,336.92$ & $\mathrm{n} / \mathrm{a}$ \\
\hline 0.9 & $1,517.03$ & $\mathrm{n} / \mathrm{a}$ \\
\hline 0.99 & $4,591.58$ & $\mathrm{n} / \mathrm{a}$ \\
\hline 1.0 & $\mathrm{n} / \mathrm{a}$ & 1,508.11 \\
\hline
\end{tabular}

For various levels of policyholder participation $(\gamma)$, stockholders calculate a fair-return premium, $P^{P^{*}}$, using the framework developed in Section 2 of the text. Parameter values are listed in Panel (a). Panel (b) contains the premiums associated with various participation levels. The premium for a fully participating mutual contract is assumed to equal $P_{0}^{*}+S_{0}$, the nonparticipating fair-return premium plus the exogenously specified stockholder equity investment.

The price for fully participating insurance issued through the mutual company is equal to $P_{0}^{*}+S_{0}=\$ 1,508.11$. The premium on fully participating insurance is therefore higher than the premium on nonparticipating insurance. This is consistent with the results of Carson and Forster (2000), who find higher prices for participating life insurance policies than for universal life insurance policies. Table 1 also reports the partially participating insurance premiums for intermediate values of $\gamma$.

The premiums in Table 1 are also consistent with the result from Section 2 that stockholders cannot profitably offer fully participating insurance. Specifically, for fully participating insurance, the maximum value for the stockholder's equity claim, $V_{e^{\prime}}^{P}$ equals $\$ 476.19$ and occurs when stockholders charge a premium of $P_{0}^{P^{*}}=\$ 10,685.64$. Even with a premium equal to ten times expected claims, the stockholders' claim is worth less than the initial paid-in equity of $S_{0}=\$ 500$. Figure 4 illustrates graphically the premiums contained in Table 1.

\section{Numerical Simulation of Policyholder Choice Problem}

The policyholder chooses the level of participation that maximizes expected utility of end-of-period wealth, given the premium schedule $P_{0^{*}}^{P^{*}} 0 \leq \gamma \leq 1$. That is, the policyholders solve: 


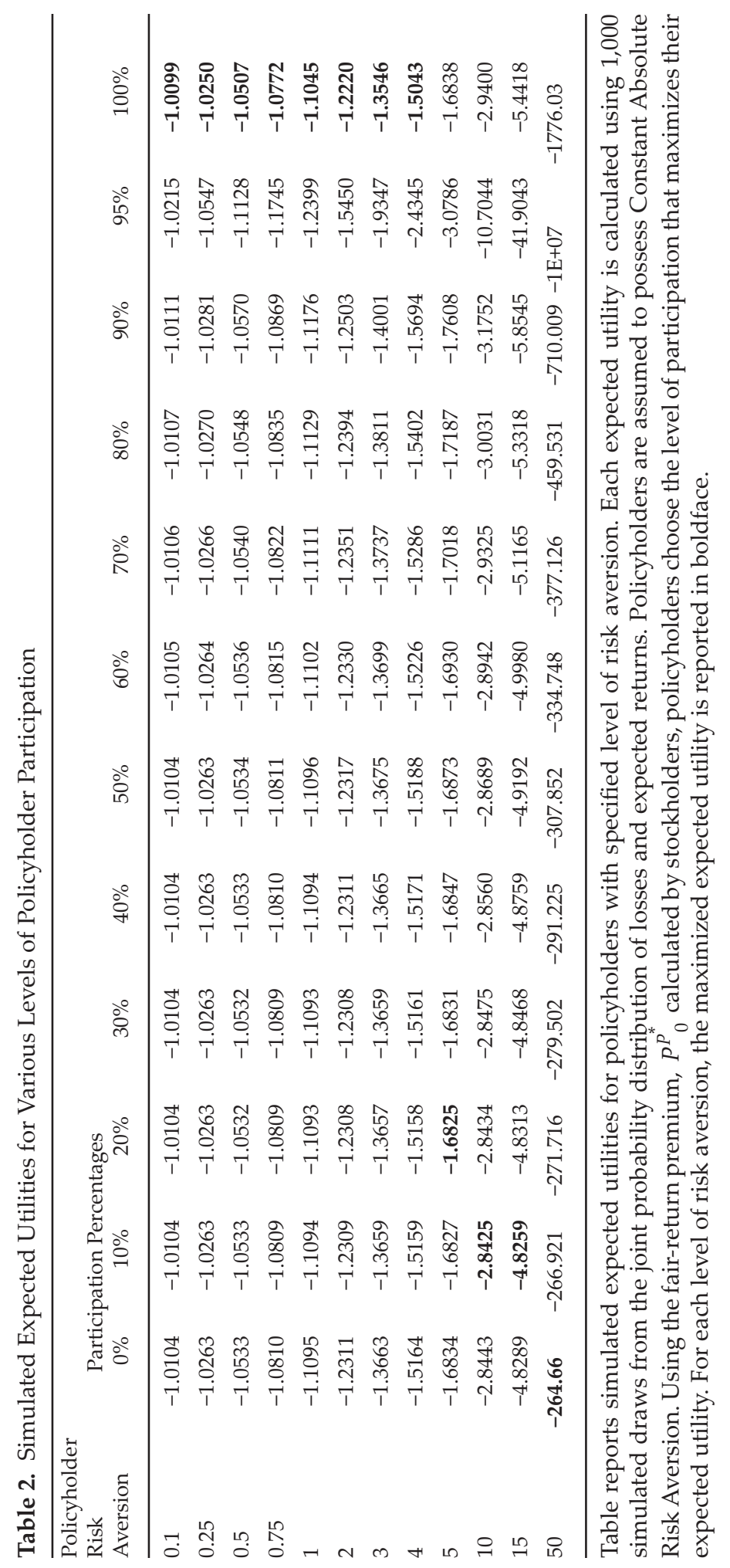




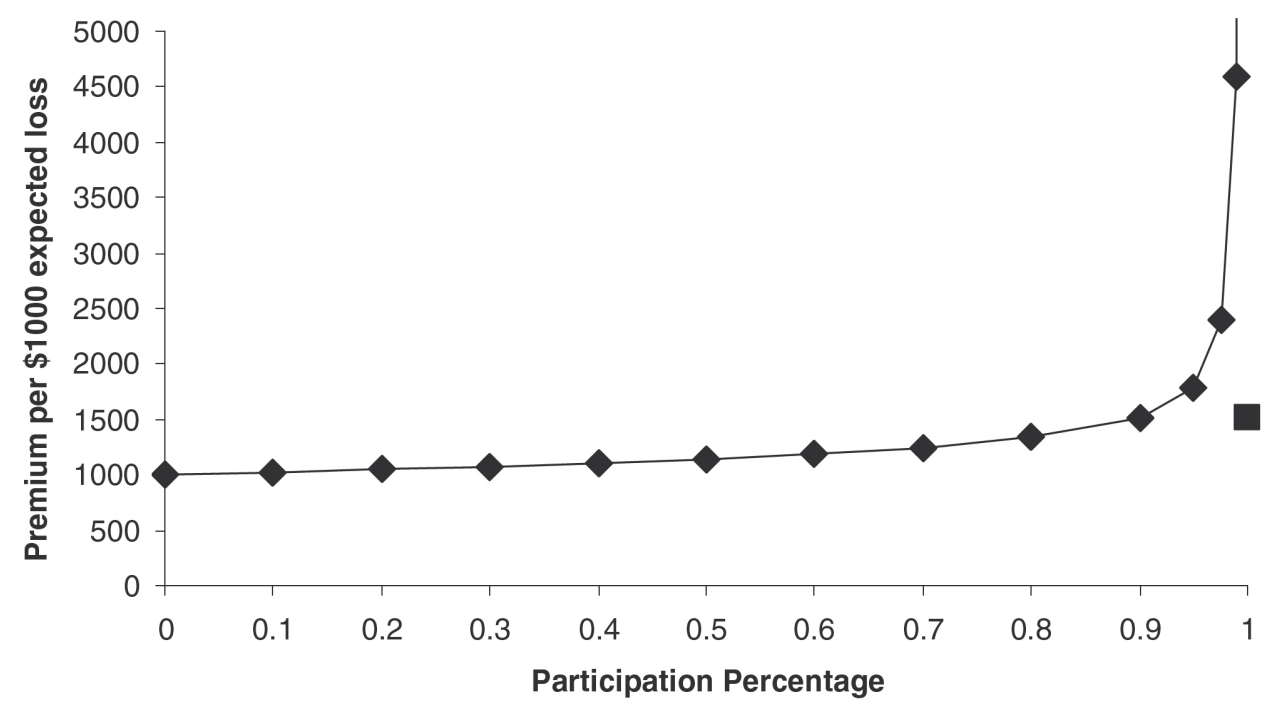

$\bullet$ Stock Co. Participating Premiums $\rightarrow$ - Fully Participating Mutual Premium

Figure 4. Premiums for Various Levels of Policyholder Participation. Figure illustrates the fair-return premium for various levels of policyholder participation $(\gamma)$. Stockholders calculate a fair-return premium, $P_{0}^{P^{*}}$, using the framework developed in Section 2 of the text. The premium for a fully participating mutual contract is assumed to equal $P_{0}^{*}+S_{0}$.

$$
\begin{aligned}
& \max _{\gamma} E\left(U\left(\tilde{W}_{1} / . W_{0}\right)\right) \\
& \text { s.t. } \tilde{W}_{1}=W_{0}-P_{0}^{P *}+\tilde{X} \quad \text { when } \tilde{X}<0 \\
& \tilde{W}_{1}=W_{0}-P_{0}^{P *} \quad \text { when } 0<\tilde{X}<S_{0} \\
& \tilde{W}_{1}=W_{0}-P_{0}^{P *}+\gamma(1-\tau)\left(\tilde{X}-S_{0}\right) \quad \text { when } S_{0}<\tilde{X} \\
& P_{0}^{P *} \leq W_{0} \text {. }
\end{aligned}
$$

Using the premium data from the previous section, we solve for the optimal level of policyholder participation as a function of risk aversion. Table 2 reports simulated expected utilities for policyholders with various levels of risk aversion. Each expected utility is calculated by simulating 1,000 draws from the joint probability distribution of losses $(\tilde{L})$ and expected returns $\left(\tilde{r}_{i}\right)$. For each simulated pair $\left(\tilde{L}, \tilde{r}_{i}\right)$, we calculate the terminal cash flow to the policyholder for various levels of policyholder participation. For each level of participation, the terminal cash flow calculation uses the fair-return premium, $P^{P^{*}}$, calculated by stockholders according to the framework in Section 2. Policyholders choose the level of participation that maximizes their expected utility. Policyholders are assumed to 
possess CARA. ${ }^{16}$ Initial wealth is assumed to equal $\$ 10,000$. Table 2 reports simulated values of expected policyholder utility over a large range of risk aversions. The maximized expected utility is reported in boldface for each level of risk aversion.

Full participation is optimal for policyholders with the lowest levels of absolute risk aversion, which is consistent with the models of Borch (1968) and Doherty and Dionne (1993). Policyholders with intermediate levels of risk aversion desire participation at relatively low levels ( $\gamma=10$ percent or 20 percent), while the most risk-averse policyholders prefer no participation at all.

Interestingly, it is never optimal for any policyholders to choose partially participating policies with participation rates above 20 percent. The reason for this is that under partially participating contracts, stockholders are fully exposed to the downside risk that end-of-period assets are less than realized claims, yet share in only a fraction, $(1-\gamma)$, of the upside gains when end-of-period assets exceed claims. In order to earn a fair expected return, stockholders must charge a very large premium in order to reduce the likelihood that end-of-period assets are deficient. These premiums are so large that no policyholder finds it optimal to buy such contracts.

Nevertheless, our model suggests that partially participating contracts with low participation levels ( $\gamma=10$ percent or 20 percent) are feasible, and Garven and Pottier (1995) and Krishnaswami and Pottier (2001) have shown that contracts are also desirable since they can mitigate agency conflicts. Yet such policies are rarely issued by stock insurance companies. For instance, Smith and Stutzer (1995) note that in 1850, stock insurer Manhattan Life offered a policy that paid a fraction of profits to policyholders and the remainder to stockholders, but also note that such instances are quite rare.

We offer a regulatory explanation for the general absence of partially participating insurance. A number of states impose regulations on stock companies limiting the extent to which the stockholders may benefit from participating business (Black and Skipper, 2000). For instance, the state of New York requires that stockholder profits on participating contracts be limited to the larger of (1) 10 percent of gains on such policies or (2) 50 cents per year per $\$ 1,000$ of participating business (\$216, New York Insurance Law). ${ }^{17}$ In the context of our model, the first limitation corresponds to a minimum value of $\gamma=0.9$. We have seen that at such high levels of policyholder participation, fair return premiums are too high to attract business. In other words, the partially participating contracts desired by policyholders aren't allowed by law, and the partially participating contracts allowed by law are undesirable to policyholders. This fundamental in-

\footnotetext{
${ }^{16}$ We have also conducted the simulations over other forms of utility, including CRRA, and the basic results are unchanged.

17 The state of Iowa also has a 10\% limit on stockholder profits (see Iowa Insurance Code $§ 521$. A5). Black and Skipper (2000) note that similar legislation exists in Canada, the United Kingdom, and other countries. While we have not verified that such regulations exist in all states, we note that insurers licensed to conduct business in New York are subject to key portions of New York laws in all states in which they do business. From a practical perspective, this extraterritorial aspect of New York law suggests that many stock insurers may face limits on participating profits such as the one we describe.
} 
compatibility is described in the case study of Fletcher (1966, p. 27), who examines the motivation for one insurance company that chose to convert from stock to mutual form:

\begin{abstract}
"If any one incident could be pinpointed as the one which led to the mutualization of this company, that event would be the decision to offer participating life insurance policies in addition to the company's nonparticipating line... When the first participating contracts were issued, the company's management took the position that all earnings on that business should be returned to the participating policyholders. The stockholders did not protest this decision because the initial profit derived from the participating policies was small. However, when the company's officers began to emphasize the participating portion of the business, there arose a conflict of views between the company's owners and management. The management persisted in returning the profits of the participating contracts to the policyholders. The owners, on the other hand, demanded that they be paid all of the profits not legally required to be paid to the participating policyholders. The officers of the company were able to enforce their view since they controlled a majority of the stock. Hence, the dividends paid to the stockholders never included any of the earnings from the participating branch of the company ... (eventually) Mutualization was proposed in order to remove the conflict of interests between management and stockholders."
\end{abstract}

As the fraction of participating business grew, stockholders were unwilling to bear the downside risk associated with these policies without also being able to participate in the potential profits. There existed a fundamental conflict between stockholders and policyholders related to the presence of participating policies, and the only way to resolve this conflict was to remove it, via mutualization.

\title{
Alternative Specification for Participating Insurance
}

An alternative specification for participating insurance is found in Garven and Pottier (1995). Our model of participating insurance differs from theirs in several ways. First, we consider a fixed expected loss, which forces the premium to vary with the participation rate. That is, for a fixed expected loss, a higher participation rate results in a higher premium. In contrast, Garven and Pottier (1995) impose a financing constraint whereby the premium is constant for all levels of participation. This produces a trade-off between expected losses and the participation rate. For a fixed premium, higher participation results in less insurance coverage. This difference between the models is somewhat superficial, as it simply amounts to two views of the same problem. Our formulation is probably more applicable to property-liability lines, where a fixed loss must be insured, while the Garven and Pottier (1995) perspective more closely mirrors a permanent life insurance contract, where the policyholder may have a fixed amount she can spend, and chooses a level of insurance coverage consistent with that amount.

To highlight the similarities between the models, Table 3 imposes a financing constraint as in Garven and Pottier (1995). We use the same parameter values from Tables 1 and 2, with the exception that the fixed premium is set at $\$ 1,000$. For various levels of participation, $\gamma$, we calculate the expected loss such that the value 
Table 3. Trade-off Between Expected Losses and Level of Participation

\begin{tabular}{|c|c|c|c|c|c|}
\hline \multicolumn{6}{|c|}{ Panel (a) } \\
\hline \multicolumn{3}{|c|}{$\begin{array}{l}P^{\mathrm{P} *}=1000 \\
\sigma_{L}=400 \\
r_{f}=5 \% \\
E\left(r_{m}\right)=12 \% \\
\sigma_{m}=20.0 \%\end{array}$} & \multicolumn{3}{|c|}{$\begin{array}{l}\beta_{i}=0.50 \\
E\left(r_{i}\right)=8.5 \% \\
\sigma_{i}=10.0 \% \\
\tau=35 \% \\
S_{0}=500\end{array}$} \\
\hline \multicolumn{6}{|c|}{ Panel (b) } \\
\hline $\begin{array}{l}\text { Participation } \\
\text { Level }(\gamma)\end{array}$ & $\begin{array}{l}\text { Stock } \\
\text { Company } \\
\text { Premium } P_{0}^{P^{*}}\end{array}$ & $\begin{array}{l}\text { Expected } \\
\text { Loss }\end{array}$ & $\begin{array}{l}\text { Market } \\
\text { Value of } \\
\text { Stockholders' } \\
\text { Claim }\left(V_{e}\right)\end{array}$ & $\begin{array}{c}\text { Market } \\
\text { Value of } \\
\text { Policyholder's } \\
\text { Claim }\left(H_{0}\right)\end{array}$ & $\begin{array}{c}\text { Market } \\
\text { Value of } \\
\text { Government's } \\
\text { Claim }\left(T_{0}\right)\end{array}$ \\
\hline 0.00 & $1,000.00$ & 991.47 & 500.00 & 928.18 & 71.81 \\
\hline 0.10 & $1,000.00$ & 970.70 & 500.00 & 924.12 & 75.87 \\
\hline 0.20 & $1,000.00$ & 947.36 & 500.00 & 919.40 & 80.60 \\
\hline 0.30 & $1,000.00$ & 920.74 & 500.00 & 913.82 & 86.18 \\
\hline 0.40 & $1,000.00$ & 889.75 & 500.00 & 907.06 & 92.94 \\
\hline 0.50 & $1,000.00$ & 852.68 & 500.00 & 898.61 & 101.38 \\
\hline 0.60 & $1,000.00$ & 806.58 & 500.00 & 887.59 & 112.41 \\
\hline 0.70 & $1,000.00$ & 745.55 & 500.00 & 872.18 & 127.82 \\
\hline 0.80 & $1,000.00$ & 655.03 & 500.00 & 847.76 & 152.24 \\
\hline 0.90 & $1,000.00$ & 476.30 & 500.00 & 795.23 & 204.77 \\
\hline 0.925 & $1,000.00$ & 383.61 & 500.00 & 766.37 & 233.63 \\
\hline 0.95 & $1,000.00$ & 208.29 & 500.00 & 709.98 & 290.02 \\
\hline 0.975 & $1,000.00$ & 0.00 & 492.07 & 649.32 & 358.60 \\
\hline 0.99 & $1,000.00$ & 0.00 & 482.09 & 659.31 & 358.60 \\
\hline 1.00 & $1,000.00$ & 0.00 & 475.43 & 665.97 & 358.60 \\
\hline 1.00 & $1,500.00$ & 991.47 & 0.00 & 1428.18 & 71.81 \\
\hline
\end{tabular}

Table reports the expected loss stockholders are willing to insure, given a fixed premium of $\$ 1,000$ combined with various levels of policyholder participation $(\gamma)$. For each level of $\gamma$, the expected loss is calculated such that the value of the stockholders' claim, $V_{e^{\prime}}$ equals the stockholders' paid-in equity, $S_{0}$. Parameter values are listed in Panel (a). Panel (b) contains the expected losses associated with various participation levels. In addition, panel (b) reports the market value of the stockholders' claim $V_{e^{\prime}}$ the policyholder's claim $H_{0}$, and the government's claim $T_{0}$. For reference, the last line of panel (b) contains the fully participating premium associated with an expected loss of $\$ 991.47$ insured through a mutual company

of the stockholders' claim, $V_{e^{\prime}}$ equals the stockholders' paid-in equity, $S_{0}$. Parameter values used in the calculation are listed in panel (a). Panel (b) contains the expected losses associated with various participation levels. In addition, panel (b) reports the market values of the stockholders' claim $V_{e^{\prime}}$ the policyholder's claim $H_{0}$, and the government's claim $T_{0}$.

A $\$ 1,000$ premium will buy a nonparticipating insurance contract covering expected claims equal to \$991.47. As in Garven and Pottier (1995), an inverse relationship exists between the fixed insurance component and the equity-based participation component. For reference, the last line of panel (b) contains the 


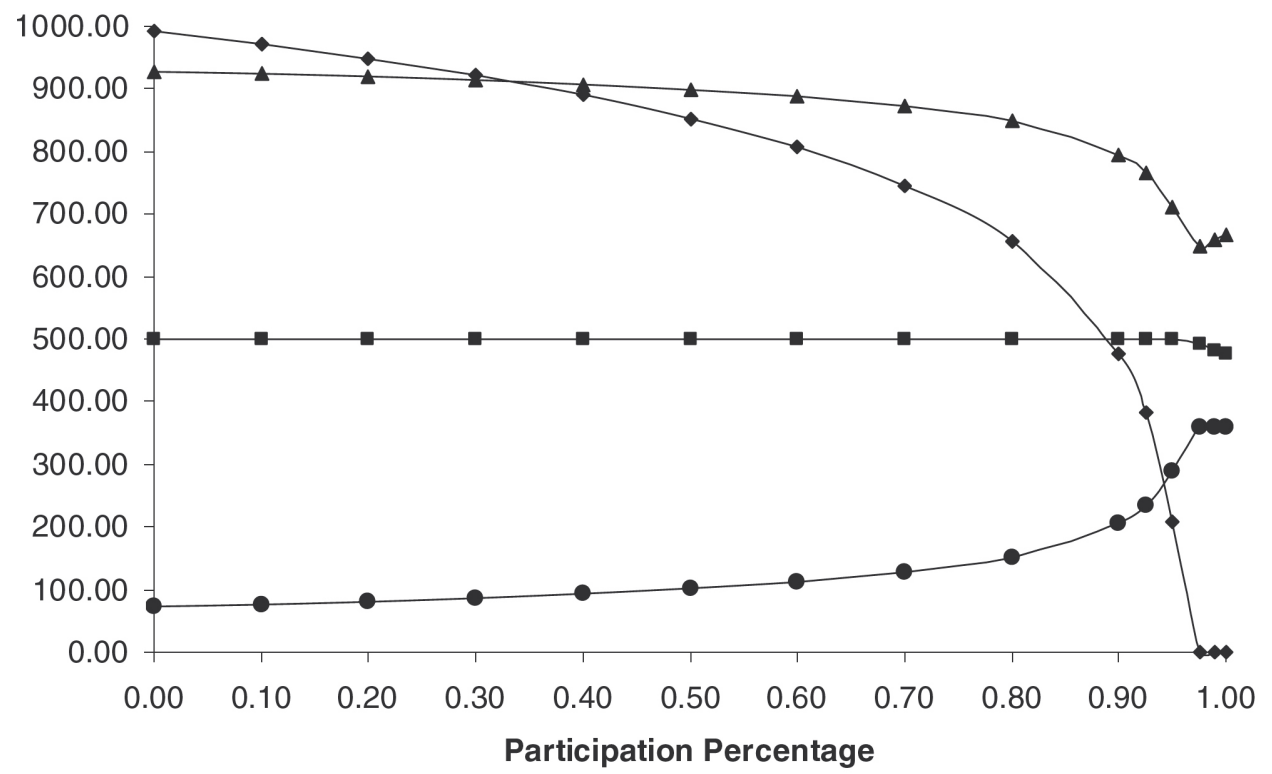

$\begin{array}{ll}\rightarrow-\text { Expected Loss } & \rightarrow-\text { Value of Shareholder Claim } \\ \rightarrow-\text { Value of Policyholder Claim } \rightarrow \text { Value of Tax Claim }\end{array}$

Figure 5. Trade-off Between Expected Losses and Level of Participation. Figure plots the expected loss stockholders are willing to insure, given a fixed premium of $\$ 1,000$ combined with various levels of policyholder participation $(\gamma)$. For each level of $\gamma$, the expected loss is calculated such that the value of the stockholders' claim, $V_{e^{\prime}}$ equals the stockholders' paidin equity, $S_{0}$. In addition, figure plots the market value of the stockholders' claim $V_{e^{\prime}}$ the policyholder's claim $H_{0}$, and the government's claim $T_{0}$.

fully participating premium associated with an expected loss of $\$ 991.47$, insured through a mutual company. ${ }^{18}$ Table 3 illustrates the tradeoff between losses and participation that results when we impose a financing constraint. Figure 5 plots the values from Table 3.

However, there are two more fundamental differences between the Garven and Pottier (1995) model and ours, and these differences are revealed in Table 3 and Figure 5. First, in addition to the policyholder and stockholders, we include the government's claim on taxable income. The government contributes no capital, yet has a valuable claim on residual income. This means that, unlike Garven and Pottier (1995), it is not possible for both the policyholder and stockholder to obtain claims with market values equal to each party's paid-in capital. We maintain the assumption that stockholders will issue insurance only when the value of their claim equals the stockholders' paid-in equity, which implies

18 This premium is equal to the $\$ 1000$ nonparticipating premium, plus the $\$ 500$ initial stockholder equity. As in the earlier numerical example, it is assumed that policyholders can "mutualize" by purchasing the stockholders' claim for its fair market value of $\$ 500$. 
that the market value of the policyholder's claim will be strictly less than the premium. ${ }^{19}$

A second difference between the models relates to the types of assets the insurance company can invest in. In Garven and Pottier (1995), the insurance company invests premiums in a positive-NPV investment with a market value in excess of the purchase price. In contrast, we assume that the insurance company must pay the market price for all investments, and thus there exists no additional surplus to be captured by policyholders or stockholders. ${ }^{20}$ Along with the presence of the government's tax claim, this second feature reinforces the result that it is not possible for both the policyholder and stockholders to obtain claims with market values equal to each party's paid-in capital.

The effect of these assumptions is readily apparent in Table 3. First, there is a direct trade-off between the value of the policyholder and government claims. For a fixed premium, a smaller fixed (insurance) component leads to a larger equity (participation) component, which increases the potential taxable income. Second, stockholders cannot profitably offer participating insurance at levels of participation above 95 percent, since the value of their equity claim is less than paid-in stockholder equity. $^{21}$

One might ask whether a policyholder would ever choose to purchase participating insurance contracts such as those in Table 3, since the policyholder's market value for nonparticipating insurance is always greater than the market value of participating insurance. The answer depends on the nature of the policyholder's loss exposure. If the policyholders face a fixed loss, then choosing a lower level of insurance coverage and a higher level of participation doesn't alter the fixed loss facing the insured; it simply means that a larger fraction of the loss is self-insured. We conduct a second simulation of policyholder expected utilities, assuming a fixed loss exposure with expected losses equal to $\$ 1,000 .^{22}$ The results are qualitatively similar to the results of the first simulation: The least risk-averse policyholders prefer fully participating insurance, issued by a mutual company; pol-

${ }^{19}$ An alternative would be to set the premium so that the market value of the policyholder's claim equals the initial premium, in which case the stockholders' claim would be worth less than initial stockholder equity. We do not choose this approach for several reasons. First, if the stockholders' objective is to maximize the value of the insurance enterprise, they would optimally forego issuing policies that reduce firm value. Second, policyholders have incentive to purchase insurance beyond a profit motive (i.e., the incentive to remove a risk exposure), and will partially insure even at actuarially unfair prices (Arrow (1974)).

20 This is not the same as assuming that stockholders' cannot make money by investing in a stock insurance company. Indeed, in our model stockholders charge a premium that produces a positive expected return consistent with the underlying investment and underwriting risk exposures. However, the investments themselves must be purchased at their fair market price. Thus, the initial value of the insurance enterprise is equal to the total paid-in capital, and value is not created by combining the premium and stockholder equity. Any excess profit accruing to stockholders comes at the expense of policyholders, and vice versa.

21 These results are sensitive to including the government's claim on taxable income in our model. In a frictionless, complete market model without taxes, stockholders would be able to profitably offer participating contracts at all levels of participation, and there would exist a continuum of policyholders who would optimally purchase these policies, with an inverse relation between risk aversion and participation.

22 These simulation results are omitted for brevity, but are available upon request. 
icyholders with intermediate levels of risk aversion optimally purchase partially participating contracts with low levels of participation; and the most risk-averse policyholders prefer nonparticipating insurance, issued by a stock company.

\section{Conclusion}

We study an equilibrium in which both stock and mutual companies are allowed to issue participating business. We assume that the mutual insurer issues only fully participating insurance, while the stock company can issue both nonparticipating and participating policies. The stock company sets premiums on both participating and nonparticipating policies to provide a fair expected return, and policyholders choose the contract that maximizes expected utility. A novel feature of our model is that we simultaneously analyze both the policyholder choice and shareholder fair-return problems.

We demonstrate that when stockholders set premiums to provide a fair expected return on their investment, stockholders will never find it optimal to offer fully participating insurance. The reason is that fully participating contracts require the stockholders to bear a certain amount of downside risk, yet exclude the stockholders from potential profits. Stockholders can profitably offer partially participating insurance. When the policyholder participation fraction is high, the stockholders' fair-return premium is so large that the utility-maximizing policyholder always prefers fully participating insurance from the mutual company. Policies with lower levels of policyholder participation are optimal for policyholders with relatively high risk aversion, and policyholders with the highest levels of risk aversion prefer nonparticipating insurance, issued by a stock company.

Our results help explain why stock insurers so rarely issue participating contracts despite their tangible benefit of reducing agency costs. We suggest that such benefits are both important and real, but that profitability or regulatory constraints may prevent stock insurers from exercising those benefits in equilibrium. Thus, our study provides one way of reconciling the empirical facts with the theoretical models and insights of Garven and Pottier (1995) and Krishnaswami and Pottier (2001). Lastly, we demonstrate that the desire to purchase participating insurance is decreasing in risk aversion.

\section{References}

Adkins, J. B., 1997, The Policyholder Perspective on Mutual Holding Company Conversions, Journal of Insurance Regulation, 16: 5-15.

Arrow, K., 1974, Essays in the Theory of Risk Bearing (Amsterdam : North Holland).

Belth, J. M., 1965, Participating Life Insurance Sold by Stock Companies (Homewood, Ill. : Irwin).

Belth, J. M., 1997, The Mutual Holding Company - A Flawed Concept, The Insurance Forum, December: 305-309.

Black, F., M. Scholes, 1973, The Pricing of Options and Corporate Liabilities, Journal of Political Economy, 81: 637-654.

Black, K., H. Skipper, 2000, Life Insurance, 13th edition (Upper Saddle River, NJ : Prentice Hall). 
Borch, K., 1968, The Economics of Uncertainty (Princeton, NJ : Princeton University Press).

Brennan, M., 1979, The Pricing of Contingent Claims in Discrete Time Models, Journal of Finance, 34: 53-68.

Carson, J. M., M. D. Forster, 2000, The Nature and Causes of Variation in Insurance Policy Yields: Whole Life and Universal Life, Journal of Insurance Issues, 23: 30-47.

Doherty, N. A., 1991, The Design of Insurance Contracts When Liability Rules are Unstable, Journal of Risk and Insurance, 58(2): 227-246.

Doherty, N. A., G. Dionne, 1993, Insurance with Undiversifiable Risk: Contract Structure and Organizational Form of Insurance Firms, Journal of Risk and Uncertainty, 6: 187-203.

Doherty, N. A., J. R. Garven, 1986, Price Regulation in Property-Liability Insurance: A Contingent Claims Approach, Journal of Finance, 41: 1031-1050.

Fairley, W., 1979, Investment Income and Profit Margins in Property-Liability Insurance: Theory and Empirical Results, Bell Journal of Economics, 10: 192-210.

Fletcher, L. P., 1966, Motivations Underlying the Mutualization of Stock Life Insurance Companies, Journal of Risk and Insurance, 33(1): 19-32.

Garven, J. R., S. W. Pottier, 1995, Incentive Contracting and the Role of Participation Rights in Stock Insurers, Journal of Risk and Insurance, 62(2): 253-270.

Gollier, C., S. Wibaut, 1992, Portfolio Selection by Mutual Insurance Companies and Optimal Participating Insurance Policies, Insurance: Mathematics and Economics, 11: 237-245.

Hill, R., 1979, Profit Regulation in Property-Liability Insurance, Bell Journal of Economics, 10: 172-191.

Jensen, M. C., W. H. Meckling, 1976, Theory of the Firm: Managerial Behavior, Agency Costs and Ownership Structure, Journal of Financial Economics, 3: 305-60.

Krishnaswami, S., S. Pottier, 2001, Agency Theory and Participating Policy Usage Evidence From Stock Life Insurers, Journal of Risk and Insurance, 68(4): 659-683.

Mayers, D., C. Smith, 1987, Corporate Insurance and the Underinvestment Problem, Journal of Risk and Insurance, 54(1): 45-54.

Pottier, S., D. Sommer, 1997, Agency Theory and Life Insurer Ownership Structure, Journal of Risk and Insurance, 64(3): 529-543.

Remmers, B., 2003, Life Insurer Demutualization in the Current Era, Journal of Insurance Regulation, 22: 75-87.

Rubinstein, M., 1974, An Aggregation Theorem for Securities Markets, Journal of Financial Economics, 1: 225-244.

Smith, B., M. Stutzer, 1990, Adverse Selection, Aggregate Uncertainty and the Role for Mutual Insurance Contracts, Journal of Business, 63: 493-511.

Smith, B., M. Stutzer, 1995, A Theory of Mutual Formation and Moral Hazard with Evidence from the History of the Insurance Industry, Review of Financial Studies, 8: 545-577.

Stapleton, K., A. Subrahmanyam, 1984, The Valuation of Multivariate Contingent Claims in Discrete Time Models, Journal of Finance, 39: 207-228. 